\title{
Sustainable pavement performance during freezing and variable immersion periods in water
}

\author{
Feras Al adday ${ }^{1}$, Hadeel Mahasneh ${ }^{2}$, Aymen Awad $^{3}$, Fatima Alsaleh $^{4}$, Nabil Elnaber $^{5}$ \\ ${ }^{1}$ Middle East University, Amman, Jordan, falkhalil@meu.edu.jo \\ ${ }^{2}$ Middle East University, Amman, Jordan, hadeelm.mahasneh@ gmail.com \\ ${ }^{3}$ Middle East University, Amman, Jordan, aawad@meu.edu.jo \\ ${ }^{4}$ Department of Transportation Engineering, Faculty of Civil Engineering, University of Aleppo, Syria, \\ alsaleh-f @alepuniv.edu.sy \\ ${ }^{5}$ Middle East University, Amman, Jordan, nabilehnaber@hotmail.com
}

\begin{abstract}
The sustainability is one of the most basic requirements for the design of asphalt mixtures, and this sustainability is due to the resistance of asphalt mixtures to mechanical strains and stresses resulting from the wheel loads generated by traffic in addition to stresses and strains produced by climatic and environmental changes. These mixtures must meet the required specifications and are economically feasible, thus obtaining optimum sustainability. The real object of this research is to study the sustainability of asphalt mixtures that use modified asphalt by waste plastic and improve its performance under cold and frosty climatic that could be exposed to the surface layer of flexible pavement, by exposing the modified asphalt samples to freezing at the temperature $(-18){ }^{\circ} \mathrm{C}$ and then expose the samples to immersion in water for 30 minutes and 24 hours. This study concluded that modified asphalt mixtures (MAM) by west plastic (WP) are better than asphalt mixtures when changing the period of freeze in case of water immersion for 30 minutes and 24 hours. The change in the flow values resulting from the freezing period changes is within a narrow range, and this is true for asphalt and modified mixtures. Flow values increase with increasing freezing hours. The lowest flow is for modified asphalt mixtures with a 30-minute immersion period. The study also concluded that the ideal period for submersion is 30 minutes, not 24 hours. As the difference between the Marshall stability values (MSV) for two cases do not exceed $8 \%$. The ratio of the asphalt added to the mixture was $5.5 \%(\mathrm{OAP})$ of the total weight of the mixture and the percentage of WP was $6 \%$ of the OAP, which gives the required specifications.
\end{abstract}

Key words: Sustainable Pavement, Modified Asphalt, Waste Plastic, and Durability.

\section{INTRODUCTION}

Asphalt pavement is considered a complex mix consisting of the three parts: Natural aggregate (filler, coarse, and fine) that represent the basic element, asphalt cement as the binder, and voids. Generally, asphalt mix is mostly consist of about 95\% aggregates and 5\% asphalt [1]. Asphalt mixtures exhibit excessive temperature susceptibility, at high temperature it becomes softer, medium temperature fatigue cracks appear, and low temperatures lead to thermal cracks [2]. The destruction of asphalt pavement is mainly due to the aging of asphalt, which contribute reduction of durability and service life of asphalt pavements. Basically, asphalt undergoes two substantially different aging processes throughout the service life. The short term aging process occurred during the production of hot mix asphalt (HMA). The long term aging process evolves with time where the asphalt is exposed to the environment as in-service pavement at a relatively lower temperature for a long duration [3]. The thermal performance of asphalt concrete is strongly dependent on the thermal properties and proportion of each material composition and the structural characteristic of asphalt concrete [4].

High ambient temperature can not only induce permanent deformation of asphalt pavement with the effect of traffic, but also accelerate the thermal oxidative ageing of asphalt material, which can degrade the durability of pavement [5]. The right determination of added substances for a specific highway project depend on interrelated components comprising the capacity of the development group, availability of materials, fetched, and the specified execution [6]. Therefore, adding supporting materials to asphalt has been investigated in multiple studies. WP is one of these materials, as its use offers a great potential in asphalt road construction, adding in small quantities, approximately 5-10 $\%$ by asphalt weight. Over a long time, plastics have gotten to be the preferred packaging fabric by ethicalness of their prevalence over other customary materials. [7]. Multiple studies, including recent and old, prove that WP has environmental and economic benefits when used in preparing asphalt mixtures [8]. WP is s derived from bottles and cans 
Feras Al adday et al., International Journal of Advanced Trends in Computer Science and Engineering, 9(3), May - June 2020, 3410 - 3416

discarded cans such as milk, water, fruit juice and cans of oil [9]. As for the quantities produced, the data of the U.S shows that entire municipal solid waste (EMSW) is approximately 2 x $10^{8}$ ton/year, a $53 \%$ of EMSW remains landfilled, a $13 \%$ of EMSW is WP [10]-[11]. In Jordan, thousands of tons of WP thrown in landfills annually. By itself, WP is one of the worst wrongdoers associated with environmental pollution [12] .Additives can interact with asphalt and form a new element and this element is characterized by new mechanical and physical mechanical properties [13]. Earlier, pavement type selected based on the economic factor and the preferred performance. At present, Sustainability entered this industry [14]. At present, any facility requiring it to be economical, environmental and meets the required specifications [15]. A sustainable highway pavement is a construction system that takes into account the waste of energy and natural materials and has a high performance [12]. WP or recycled rubber may be added to mixtures of asphalt by dry and wet technique [16] and [17]. Paul and Bhattacharya have covered aggregates WP, their study concluded that the addition WP gives better performance and greater durability, in addition to reducing the aggregates 'absorption of water [18]. Al-Humeidawi also did in his research where he covered the aggregates with plastic bags in production of HMA mix. He was indicated that the stability increased up to $10 \%$, and tensile strength increased equal to $9 \%$ related to reference mixtures [19]. The same result is reached by Chavan when using regular purchase bags, he also shows that the asphalt percentage can be reduced by $10 \%$ [20].

The opposite procedure was completed by Sevil Köfteci the wet technique was used, where PW added to the pure asphalt with $1,2,3$, and $4 \%$ of pure asphalt content. The results showed that the using of $4 \%$ has an improved properties in terms of Marshal Stability. Moreover, the MAM have a high water resistance [21]. The dry technique also used by Adou. The results stated that PW has a positive effect on the properties of aggregates, as it increases the resistance to abrasion, higher soundness and lower water absorption. This, in turn, increased the stability by $15 \%$ [22].

The impacts of freezing-thawing and ageing on mechanical properties and warm characteristics of conductive asphalt concrete (CAC) were experimentally examined by Pan Pan a,b et al studies. Control asphalt concrete tests were arranged by the same total gradation and volume composition with CAC. Exploratory comes about demonstrated that freezing-thawing impact would lead to volume extension and quality debasement of CAC tests. Amid the freezing-thawing test, the thermal conductivity and particular warm of CAC tend to diminish [23]. Feras Al adday et al studied durability indexes for modified asphalt, where freeze-thaw stresses have determined. Three sorts of asphalt blends were arranged agreeing to the Marshall test, freeze-thaw cycles were 1, 2, 3, 4 , and 5 cycles, where each cycle include 48 hours $(24 \mathrm{~h}$ freezing and $24 \mathrm{~h}$ thawing). Polyethylene and WP added to asphalt mixes. The results showed that the modified mixes with WP have more durability from asphalt mix [24].

\section{METHODOLOGY}

Marshall Investigation has been adopted to accomplish this research (ASTM D 1559-89). Samples were compacted by means of dynamic compaction apparatus with 75 blows on the bottom and the top of samples face at $140-145^{\circ} \mathrm{C}$. The first phase involved the preparation of the aggregates and asphalt. Table 1 shows a summary of the experiments carried out on the asphalt and Table 2 and table 3 shows the properties of the aggregates. The optimum asphalt percentage (OAP) was $5.5 \%$ of the total weight of specimens, where the percentages of asphalt used to prepare asphalt samples were as follows: 4 . $4.5,5,5.5,6$, and $6.5 \%$ by entire weight of mixtures, depend on the environmental conditions and general requirements in Jordan [25]. WP is a disposable bags that are thrown in household waste, involving transparent and colored carry bags brought from residential zones. These bags were cut manually into a small units from 1 to $3.4 \mathrm{~mm}$, a 0.96 was value of specific gravity of WP (ASTM D792). WP was mixed with the asphalt according to the following method. The temperature of mixing asphalt with WP was 160 to 170 , at this temperature, the shredded WP is melted in the asphalt, and then were stirred by hand from a 20 to 30 minutes in order to achieve a homogeneous mixture as possible. Changed quantities of WP were replaced of OAP as follows: 0, 2, 4, 6, 8,10 and $12 \%$ of OAP. Optimum modified asphalt percentage (OMAP) was $6 \%$ of the OAP, WP has been added to the hot aggregates at a temperature of $180{ }^{\circ} \mathrm{C}$ to produce modified asphalt mixtures.

The last stage is the examination phase of the resistance of asphalt mixtures to freezing and water for various periods, this stage consists of two tests. First, freezing temperature $(-18){ }^{\circ} \mathrm{C}$ was adopted, as samples were placed in the freezer according to time periods $(6,12,24,48$, and 96$)$ hours, then extracted from the freezer and left at the laboratory temperature for 24 hours, and then the samples were placed in a water bath at $60^{\circ} \mathrm{C}$ for 30 minutes, it is directly tested by the Marshall method. Second, samples were placed in the freezer according to time periods $(6,12,24,48$, and 96$)$ hours, where the freezing temperature was $\left(-18{ }^{\circ} \mathrm{C}\right)$, and then extracted from the freezer and left at the laboratory temperature for 24 hours, and then the samples were placed in water bath at 60 ${ }^{\circ} \mathrm{C}$ for 24 hours, as it is directly tested by Marshall method. The stages of the research can be summarized by methodological Figure 1. The total numbers of Marshall samples is 180, 126 samples to choose OCP and OMCP, 54 samples to test the behavior of asphalt samples under freezing and immersion in water for 30 minutes and 24 hours. 
Table 1: Shows the physical properties of the asphalt

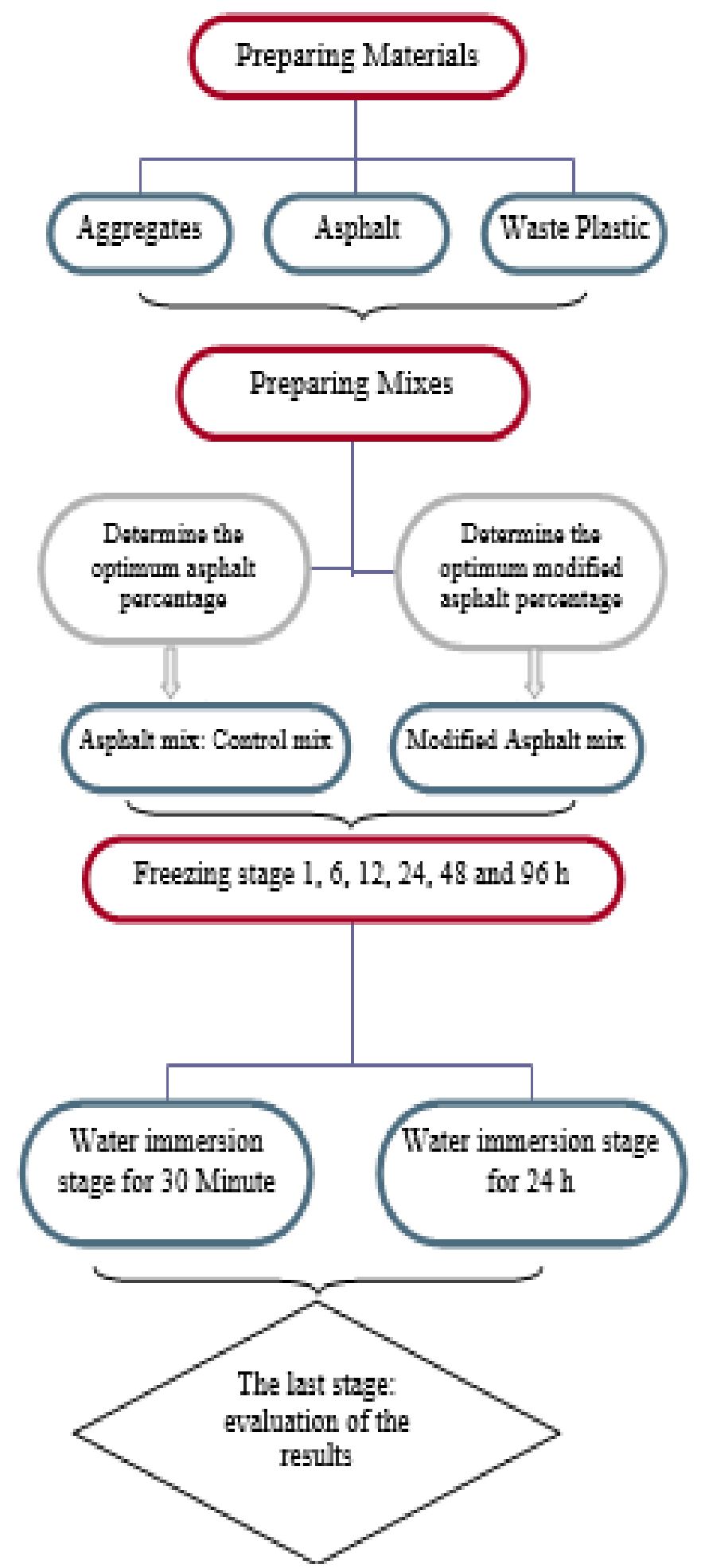

Figure 1: Shows summary of the research stages

\begin{tabular}{ccc}
\hline Examination & $\begin{array}{c}\text { Measured } \\
\text { value }\end{array}$ & $\begin{array}{c}\text { Standard } \\
\text { Method }\end{array}$ \\
\hline $\begin{array}{c}\text { Specific gravity } \\
\text { Test }\end{array}$ & 1.04 & ASTM D-70 \\
\hline $\begin{array}{c}\text { Softening point } \\
\text { Test }\end{array}$ & $50{ }^{\circ} \mathrm{C}$ & ASTM D-36 \\
\hline Ductility Test & $80 \mathrm{~cm}$ & ASTM D113 \\
\hline Penetration Test & $65 \mathrm{~mm}$ & ASTM D-5 \\
\hline Fire point Test & $319^{\circ} \mathrm{C}$ & AASHTO T48 \\
\hline Flash point Test & $282^{\circ} \mathrm{C}$ & AASHTO T48 \\
\hline
\end{tabular}

Table 2: Aggregate properties

\begin{tabular}{|c|c|c|c|}
\hline $\begin{array}{c}\text { L. A. Abrasion } \\
\text { (ASTM } \\
\text { C131-81) }\end{array}$ & \multicolumn{3}{|c|}{$27 \%$} \\
\hline $\begin{array}{c}\text { Specific Gravity } \\
\text { (ASTM C127 } \\
\text { (2012a)) }\end{array}$ & $\begin{array}{c}2.59 \\
\text { Coarse } \\
\text { aggregate }\end{array}$ & $\begin{array}{c}2.61 \\
\text { fine } \\
\text { aggregate }\end{array}$ & $\begin{array}{l}2.71 \\
\text { filler }\end{array}$ \\
\hline $\begin{array}{c}\text { Water } \\
\text { Absorption } \\
\text { ASTM C127 } \\
\text { (2012a) }\end{array}$ & $1.6 \%$ & $1.94 \%$ & $2.1 \%$ \\
\hline \multicolumn{4}{|c|}{ Table 3: Aggregate Gradation (ASTM C131) } \\
\hline \multirow{2}{*}{ \# Sieve } & \multicolumn{3}{|c|}{ Passaging (\%) } \\
\hline & Fine & \multicolumn{2}{|c|}{ Coarse } \\
\hline 1 in & 100 & \multicolumn{2}{|c|}{100} \\
\hline $3 / 4$ in & 100 & \multicolumn{2}{|c|}{97} \\
\hline $1 / 2$ in & 100 & \multicolumn{2}{|c|}{60.65} \\
\hline $3 / 8$ in & 100 & \multicolumn{2}{|c|}{33.59} \\
\hline$\# 4$ & 99 & \multicolumn{2}{|c|}{2.88} \\
\hline$\# \mathbf{8}$ & 86 & \multicolumn{2}{|c|}{0.57} \\
\hline$\# 16$ & 50 & \multicolumn{2}{|c|}{0} \\
\hline \#30 & 30 & \multicolumn{2}{|c|}{0} \\
\hline \#50 & 16 & \multicolumn{2}{|c|}{0} \\
\hline No.200 $(75 \mathrm{mc})$ & 7 & \multicolumn{2}{|c|}{0} \\
\hline
\end{tabular}

\section{RESULTS AND DISCUSSION}

\subsection{Estimate the OCP and OMCP}

WP is added according to specific ratios to asphalt which is also a variable proportions, so that a modified asphalt bond is formed, and then samples are prepared using the modified asphalt bond while maintaining other materials formed for the asphalt mixtures. The physical and mechanical properties of the MAM are determined. The next five Figures illustrate the relationship of asphalt ratios of 4. 4.5, 5, 5.5, 6, and 6.5\% with a variable ratio for WP of $0,2,4,6,8,10$ and $12 \%$ of 
OAP versus the voids ratio, specific gravity, flow, stability, and voids in mineral aggregates (VMA).

Increasing the asphalt and WP ratio results in a noticeable increase in stability, but until the value of $6 \% \mathrm{WP}$, and 5.5\% asphalt, but after this maximum value, any increase leads to a decrease in stability. The poor behavior of MAM occurs when increasing the WP and asphalt which leads to formation of a small solid parts of the WP, which in turn lead to a lack of stability. Good behavior up to 6\% of WP and 5.5\% asphalt, due to an increased asphalt bonding property as showed in Figure 2. For flow curves, unlike stability as presented in Figure 3, the curves are observed to decrease to a minimum value and then rise, this behavior may due to the making of a harder blend. And the fact that the flow and stability are associated with an inverse relationship [25].

With regard to specific gravity, its curves tend to decrease with the increase in the ratio of asphalt and WP as presented in Figure 4, and this behavior returns, as was previously indicated, by the formation of the solid bodies of the WP. Relating to voids ratio, its patterns are opposite to specific gravity patterns in terms of behavior as shown in Figure 5. In other words, the percentage of voids increase with increasing the asphalt and WP, where increasing of WP (a stiffer particles) leads to a decrease in the aggregate stacking capacity. Therefore, a higher voids [26]. The durability of HMA is affected by the asphalt thickness surrounding the aggregates. With the purpose of achieve a good durability, the VMA must be less [27]. As it seems clear from the Figure 6, the increase in VMA relates to an increase in WP proportion. The OMAP are 6 of OAP, where OAP was $5.5 \%$ by entire asphalt weight in relation to maximum stability values, $\underset{1400}{\operatorname{maximum}}$ specific gravity values, and $4 \%$ of void ratio.

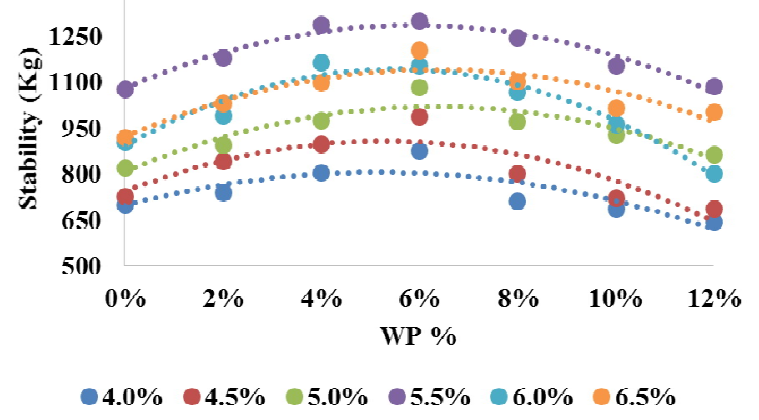

Figure 2: Asphalt and WP percent VS stability

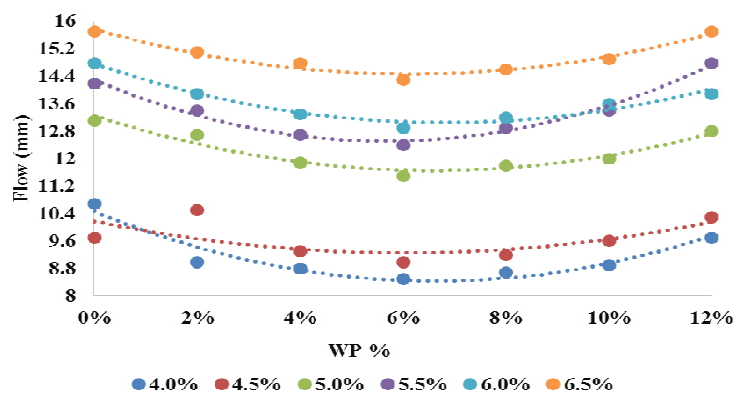

Figure 3: Asphalt and WP percent VS flow

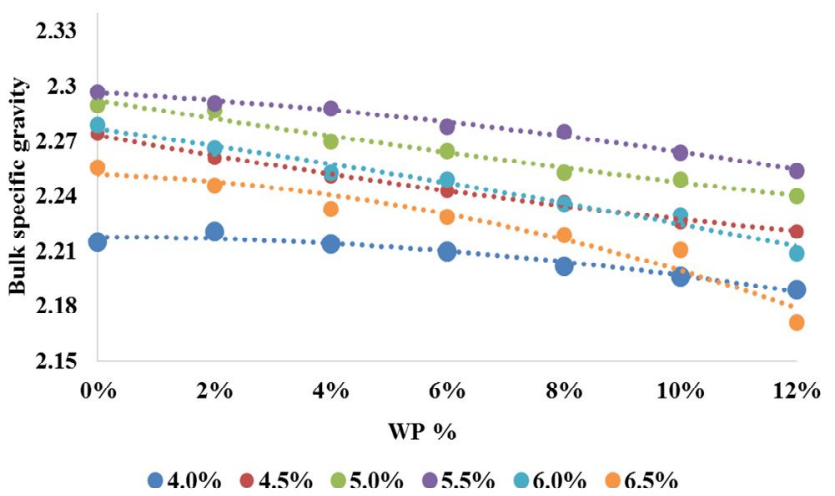

Figure 4: Asphalt and WP percent VS specific gravity

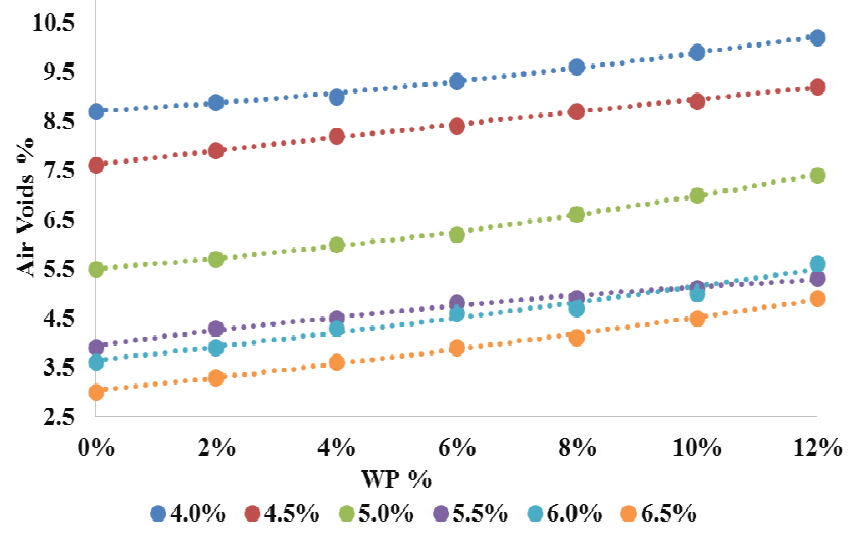

Figure 5: Asphalt and WP percent VS air voids

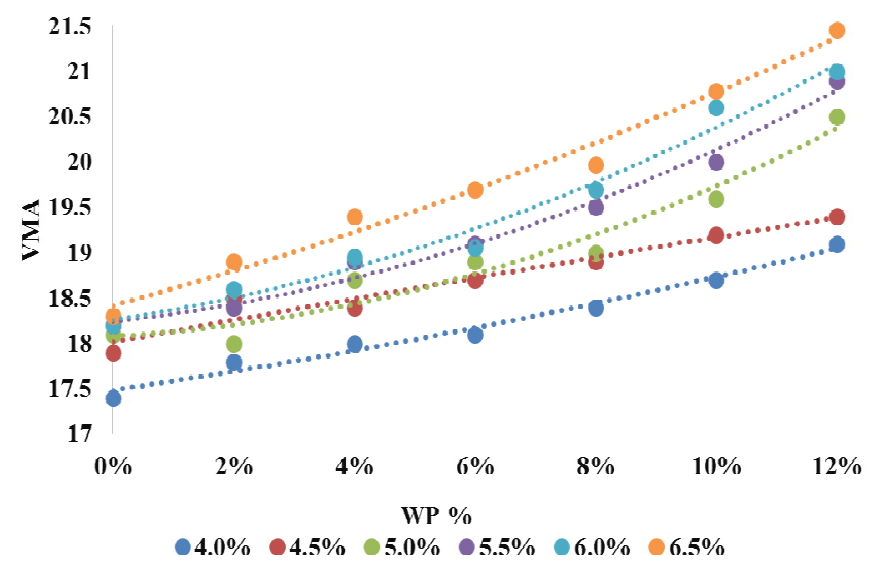

Figure 6: Asphalt and WP percent WP VS VMA

\subsection{The Effect of the Duration of the Freeze by Immersing the Samples in Water for 30 Minutes and 24 Hours.}

Freezing temperature $(-18){ }^{\circ} \mathrm{C}$ was adopted, the samples have placed in the freezer according to periods $(6,12,24,48$, and 96) hours, then extracted from the freezer and left at the laboratory temperature for 24 hours, and then the samples were placed in a water bath at $60{ }^{\circ} \mathrm{C}$ for 30 minutes and 24 hours, it is directly tested by the Marshall method. 


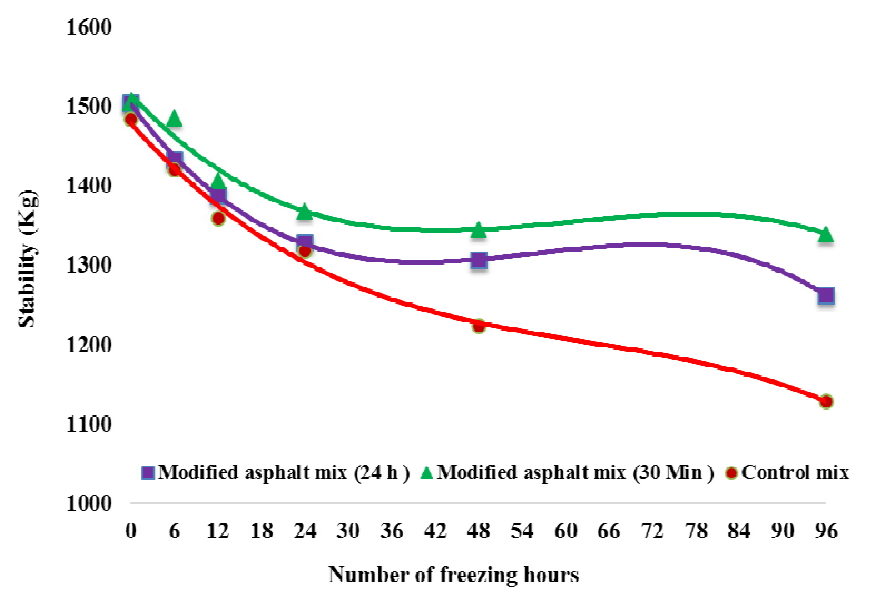

Figure7: The relationship between hours of freezing and stability

There is a significant difference between the Marshall Stability values (MSV) between the asphalt mixtures and the MAM by WP, almost $20 \%$ increase in MSV at 96 hours immersion in water as shown in Figure 7. The change in the MSV is a simple and limited. It is noted that the resulting decrease in these values for MAM with a period of water immersion of 30 minutes does not exceed $2 \%$ of the reference samples (without freezing) at the freezing period of 6 hours, For a period of 12 hours, the percentage of the decrease is 7 , and for a period of 24 hours, it decreases by $10 \%$. For a period of 48 hours, the shortage is by $11 \%$, and the maximum decrease in MSV at (96) hours does not exceed $12 \%$ of the reference sample. For MAM with a 24-hour immersion period, the MSV have values less than 30 minutes of water immersion. For example the greatest decrease in MSV in 96 hours freezes $20 \%$, in asphalt mixtures related to the reference samples.

By increasing the freezing period, the MSV decreases, this is due to the shrinkage of the asphalt surrounding the aggregates shrinks and thus increases its viscosity (greater hardening), with the increase in temperature after taking it out from the freezer and placing it at the laboratory temperature for 24 hours, the asphalt expands with high temperature, causing cracks and tearing of the asphalt, so the water leaks into the pores and air voids, so a state of saturation of the voids leads to weakening the adhesive and cohesion property of the asphalt bond. Then instability occurs, the fragmentation and stripping of the aggregate from the asphalt bond, and these mixtures collapse, thereby decreasing the MSV. From the foregoing it is clear that the MAM with WP suffer the least change when exposed to variable periods of freezing, and this leads to the use of WP as an improvement of the asphalt mixtures leading to an improvement of the adhesion and adhesion properties of the asphalt and thus a positive impact on the mechanical properties of the asphalt mixtures.

The effect of increasing the duration of submerging samples with water from 30 minutes to 24 hours is evident on the MSV, as these values decrease more than in the case submerging of samples in water for 24 hours. By selecting 30 minutes, the effort and time to immerse the samples in water can be maintained instead of 24 hours. The study concluded that the ideal period for submersion is 30 minutes, not 24 hours. As the difference between the MSV between the two cases does not exceed $8 \%$. With regard to the flow, which is considered one of the most important indicators of the good performance of asphalt mixtures, against the freezing and thawing state [28]. The change in the flow values resulting from the freezing period changes is within a narrow range as shown in Figure 8, this is true for asphalt and modified mixtures. Flow values increase with increasing freezing hours. Note that the lowest flow is for MAM with a 30-minute immersion period. This confirms the ideal water-benefit period at 30 minutes instead of 24 hours with the same freezing periods.

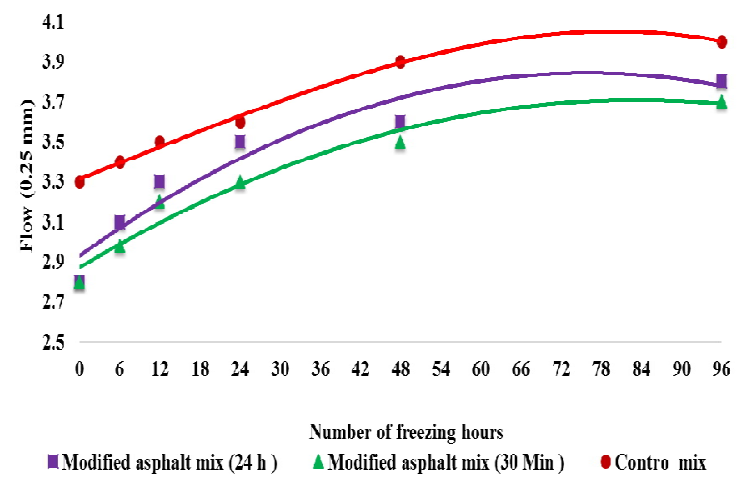

Figure 8: The relationship between hours of freezing and flow

Flow values increase as the freezing period increases with a rate of almost constant for all mixtures used in this research, this is due to the action of both freezing and water in washing, oxidizing and tearing the asphalt-film surrounding the aggregate, which becomes more fragile and thus weakening the adhesive and cohesion properties, consequently disintegration and defect in the fabric of the asphalt mixtures occurs, resulting in greater flow as the freezing period increase.

\section{CONCLUSION}

A wide range of asphalt mixture samples and MAM have been completed, the relationship between each of the mechanical properties of these mixtures and the time periods of submersion in water are inferred when exposed to variable periods of freezing. The following are simplified to clarify those results. The ratio of the asphalt added to the mixture was $5.5 \%$ (OAP) of the total weight of the mixture and the percentage of WP was $6 \%$ of the OAP, which gives the required specifications. 
Feras Al adday et al., International Journal of Advanced Trends in Computer Science and Engineering, 9(3), May - June 2020, 3410 - 3416

MAM are better and more sustainable than asphalt mixtures, when changing the period of freeze at 30 minutes and 24 hours of water immersion. Increasing the immersion period for samples from 30 minutes to 24 hours will clearly affect the MSV, as these values exceed $8 \%$ at 30 minutes over submerging the samples with water for 24 hours. The use of $\mathrm{WP}$ as an additive for asphalt mixtures assistances to increase the resistance of the asphalt mixtures to freezing damage and water action (immersing the samples in water for $30 \mathrm{~min}$ and $24 \mathrm{~h}$ ). The change in the flow values resulting from the freezing period changes is within a narrow range, this is true for asphalt and modified mixtures. Flow values increase with increasing freezing hours. The lowest flow is for MAM with a 30-minute immersion period. The study concluded that the ideal period for submersion is 30 minutes, not 24 hours. As the difference between the MSV between the two cases does not exceed $8 \%$. By selecting 30 minutes, the effort and time to immerse the samples in water can be maintained instead of 24 hours. As a general result of this research, modified mixtures with Waste Plastic is one of the forms of sustainable paving, low cost, environmentally friendly, and with specifications compatible with the required standard specifications.

\section{ACKNOWLEDGEMENTS}

The authors are grateful to the Middle East University, Amman, Jordan for their financial support for the publication of this research article.

\section{ACKNOWLEDGMENT}

The authors are grateful to the Middle East University, Amman, Jordan for the financial support granted to cover the publication fee of this research article.

\section{REFERENCES}

1. Hanaa Khaleel Alwan Al-Bayati, Susan. Tighe, Jessica Achebe, 2018. Influence of recycled concrete aggregate on volumetric properties of hot mix asphalt. Journal homepage: ww.elsevier.com/locate/resconrec. Resources, Conservation \& Recycling 130 (2018) 200-214.

2. Sulyman, M., Haponiuk, J. and Formela, K.,2016, Utilization of Recycled Polyethylene Terephthalate (PET) in Engineering Materials: A Review. International Journal of Environmental Science and Development. ,

DOI: http://www.ijesd.org/vol7/749-A707.pdf.

3. Mohd Ezree Abdullah1,a, Kemas Ahmad Zamhari2,b, Rosnawati Buhari3,c,Mohd Nafarizal Nayan 4,d, and Mohd Rosli Hainin,2013, Short Term and Long Term Aging Effects of Asphalt Binder Modified with Montmorillonite, Key Engineering Materials, doi:10.4028/www.scientific.net/KEM.594-595.996.

4. Pan, Pan \& Wu, Shaopeng \& Xiao, Yue \& Liu, Gang, 2015. A review on hydronic asphalt pavement for energy harvesting and snow melting, Renewable and
Sustainable
Energy
10.1016/j.rser.2015.04.029.
Reviews, DOI:

5. T.Y. Zhu, T. Ma, X.M. Huang, S.Q. Wang,2016. Evaluating the rutting resistance of Asphalt mixtures using a simplified triaxial repeated load test, Construction and Building Materials, https://doi.org/10.1016/j.conbuildmat.2016.04.102.

6. Johnson Kwabena Appiaha, Victor Nana Berko-Boatenga, Trinity Ama Tagbor,2017, Use of waste plastic materials for road construction in Ghana. Case Studies in Construction Materials, doi.org/10.1016/j.cscm.2016.11.001.

7. K.V.R.Prasad, Dr S.P..Mahendra, Dr N. S. Kumar, 2015. Use of pet (poly ethylene teraphtalate) waste in bituminous road construction -a Critical review. International Journal of Emerging Technologies and Engineering (IJETE),

http://www.ijete.org/wp-content/uploads/2015/04/140260.pdf.

8. Xue, Y., Hou, H., Zhu, S., \& Zha, J, Utilization of municipal solid waste incineration ash in stone mastic asphalt mixture: pavement performance and environmental impact. Construct Build Mater 209; 23:989-96.

9. Feras Al Adday, Fatima Alsaleh, 2020. Study the Possibility of Using the Modified Asphalt Mixtures with Waste Plastic in High-Temperature Areas. International Journal of Emerging Trends in Engineering Research. Volume 8. No. 4. doi.org/10.30534/ijeter/2020/23842020.

10. Tanja Narancic and Kevin E. O'Connor, 2019. Plastic waste as a global challenge: are biodegradable plastics the answer to the plastic waste problem? Narancic and O'Connor, Microbiology 2019;165:129-137. DOI 10.1099/mic.0.000749.

11.Feras $\mathrm{Al}$ adday, 2018, Eco-Friendly Hot Mix Asphalt by Using Recycled Concrete Aggregate and Waste Plastic. International Journal of Civil Engineering and Technology (IJCIET). Volume 9, Issue 7, July 2018, pp. 226-236, Article ID: IJCIET_09_07_023. Available online at http://www.iaeme.com/ijciet/issues.asp?JType=IJCIET $\&$ VType $=9 \&$ IType $=7$.

12. Haopeng Wang, Xueyan Liu, Panos Apostolidis, Tom Scarpas, (2018). Review of warm mix rubberized asphalt concrete: Towards a sustainable paving technology. journal of cleaner production, 177 (2018) 302-314. DOI: 10.1016/j.jclepro.2017.12.245.

13.Huaxin, Chen., Qinwu, Xu., \& Xi'an, 'Experimental study of fibers in stabilizing and reinforcing asphalt binder". Elsevier Ltd. All rights reserved, TX 78712, USA: 2009.

14. Brian Prowell, (2008). Carbon Footprint: How Does HMA Stack Up?. Report used with Permission of the National Asphalt Pavement Association. Summer 2008.

15.Haifang Wen, Jian Lu, Timothy M. VanReken, (2014). Modeling the effect on energy and carbon dioxide from the use of recycled asphalt pavement in hot mix 
asphalt. International journal of sustainable transportation, ISSN: 1556-8318/ 1556-8334 online, November 2014.

16.Zainab Z. Ismail, Enas A. AL-Hashmi, (2007). Use of waste plastic in concrete mixture as aggregate replacement. ELSEVIER journal, Available online at www.sciencedirect.com, waste Management 28 (2008) 2041-2047.

17. Aymen Awad, 2020. Guidelines for Civil Structures Demolition Method Selection to Enhance Environmental Protection. International Journal of Emerging Trends in Engineering Research, Volume 8. No. 2, doi.org/10.30534/ijeter/2020/11822020.

18. Rajdip Paul and Debashis Bhattacharya, 2015. Use of waste plastic in construction of road. Global journal of engineering science and researches, ISSN 2348 - 8034, Paul, 2(6), June 2015.

19. Basim H. Al-Humeidawi, (2014). Utilization of Waste Plastic and Recycle Concrete Aggregate in Production of Hot Mix Asphalt. Al-Qadisiya Journal for Engineering Sciences, Vol. 7, No. 4. October 2014.

20. Miss Apurva J Chavan, 2013. Use of plastic waste in flexible pavements. International Journal of application or innovation in engineering and management (IJAEM). Volume 2, Issue 4.

21. Hanaa Khaleel Alwan Al-Bayati, Susan. Tighe, Jessica Achebe, 2018. Influence of recycled concrete aggregate on volumetric properties of hot mix asphalt. Journal homepage: www.elsevier.com/locate/resconrec. Resources, Conservation \& Recycling 130 (2018) 200-214.

22. Freshnel Adou, Boateng Ampadu, Nana Kwesi Agyepong, and Olivia Naa-Afi Soli. 2018. Assessing Plastic Waste Usage as Additives in Flexible Asphalt Mix for Road Construction. Civil and Environmental Research. ISSN 2224-5790 (Paper) ISSN 2225-0514 (Online).

23. Pan Pan a,b, Shaopeng Wub, Xiaodi Hu a, Peng Wang b,c, Quantao Liu b, 2017. Effect of freezing-thawing and ageing on thermal characteristics and mechanical properties of conductive asphalt concrete, Construction and Building Materials. http://dx.doi.org/10.1016/j.conbuildmat.2017.02.135

24. Feras al adday, 2019. Short term freeze-thaw effects on waste plastic bags and industrial polyethylene modified hot mix asphalt (hma). International journal of current research, doi: https://doi.org/10.24941/ijcr.34971.04.2019.

25. Aymen Awad, Firas Al Bajari and Feras Al Adday, 2019. A Case Study on Rainwater Harvesting and Reuse in Jordan. International Journal of Emerging Trends in Engineering Research Volume 7. No. 11, https://doi.org/10.30534/ijeter/2019/017112019.

26. Esmaeil Ahmadinia, Majid Zargar, Mohamed Rehan Karim, Mahrez Abdelaziz, Payam Shafigh, 2011. Using waste plastic bottles as additive for stone mastic asphalt. Materials and Design, doi:10.1016/j.matdes.2011.06.016.
27. Rajib B. Mallick and Tahar El-Korchi, 2018. Pavement Engineering Principles and Practice. Third Edition, () 2018 by Taylor \& Francis Group, LLC.

28. Aymen Awad and Feras Al adday, 2017. Utilization of waste plastics to enhance the performance of modified hot mix asphalt. International Journal of GEOMATE, Dec., 2017, Vol. 13, Issue 40, pp. 132-139. DOI: https://doi.org/10.21660/2017.40.170603. 